\title{
Body Parts Expressions between Praising and Condemning; "An Arabic-English Contrastive Study with Implications for Translation"
}

\author{
Rewaa Ahmed Anwer* \\ rewaa.anwer@art.svu.edu.eg
}

\section{Abstract}

Expressions including names of body parts behave differently in Arabic and English. Most of these expressions are used to indicate meanings beyond the body parts involved in them. Body parts expressions are used to condemn and also to praise. Translating such expressions needs the human translator to be fully aware of the cultural differences between the two languages to avoid deforming the messages intended in the source language. Translating these expressions using the regular machine translation programs will be completely misleading in most of the cases unless these programs are given enough data regarding the real, non literal meanings of these expressions.

In Arabic, we use the expression/ma?Su:f-i rraPabah/ 'one with a fractured neck' to indicate that someone has been behaving in a disrespectful way. An expression like that is not familiar in English. Its expected literal translation for someone who is not common in the Arabic culture is "Neck pounded" or "with a pounded neck" and its machine translation version in programs such as 'Google translate' and 'Yandex translate' is "Neck cannon". The solution to avoid such an inadequate translation is to use alternatives carrying the meaning of someone behaving rudely or impolitely. These alternatives manage to bridge the cultural gap between the two languages reaching the most adequate version of translation.

Key Words: Body-parts expressions, condemning; praising, translation gap, machine translation, cultural gap, translation alternatives

*English Dept., Faculty of Arts, South of Valley University

(Body Parts Expressions between Praising and Condemning...)Dr. Rewaa Anwer 


\section{Introduction}

This paper examines the phenomenon of using body parts expressions in both Arabic and English in regular conversations to indicate meanings which have nothing to do with the parts of the body employed in such expressions. The two languages under investigation employ the use of body parts expressions in a wide range, sometimes to praise, promise and compliment. Some other times they are used to condemn, threaten and insult.

\section{Consider the following examples:}
A) /lamma
$y u^{e} u D$
Pafa:h/
when.adv
he.pro.bite.v.prsnt
his.nape.acc
‘*When he bites his nape'
'Impossible', 'No way'
B) /lamma yushu:f Halamit widnuh/
when.adv. he.pro.see.v. his.earlap.acc his.ear.gen.
prsnt

'*When he sees his earlap'

'Not a chance'

The Arabic expression in (A) is used to indicate that something is impossible to happen through the use of /lamma $\mathrm{yu}^{\mathrm{c} u D}$

Pafaah/.That expression implies that something is only going to happen when a person can actually bite his own nape is a common expression in Arabic used to say that something is impossible.

Using the English literal translation is vague since that expression is not common in English. 
In (B) the same message is expressed through using another body part which is also impossible to see/lamma yushu:f Halamit widnuh/.

The literal translation of the two expressions above might seem ambiguous for the target language readers because they are not commonly used in English, that's why alternatives carrying the meaning of impossibility such as "Don't even dream of it" or "not a chance in hell" are suggested.

Using Google translation; these two expressions were incompetently translated as "when he bites his thighs" and "When he shows his nipple".

Other Arabic expressions are not ambiguous when translated literally, but they carry different meanings than the ones intended in the source text.

\section{Consider the following example:}

(C) $\mathrm{Pi}: \mathrm{duh}$

his.hand.nom.

'*He is long handed'

'*His hands are long'
Tawi:lah

long.adj..

The literal translation of the expression (C) is not odd as the ones in (A and B) but it fails to deliver the message intended in the source language. In Arabic, that expression means that someone is taking something which he is not supposed to take (as in the act of theft or using one's power, money or authority to reach his aim). 
The literal translation, even though being fully meaningful, is not an adequate translation since it doesn't deliver the message intended in the source language because the English expression longhand means that someone writes a text avoiding the use of any shortened forms or abbreviations. An alternative such as 'he is a thief' or 'He is taking advantage of his authority' would be much more adequate in that context.

"Long hands" and "his hands are long" are the translation versions of Google and Yandex. Both versions are inadequate since they don't deliver the message intended in the Source language.

Another category of Arabic expressions employing the use of body parts is the one in which the English language uses the same expression and in the same way, but with slight changes in its structure as in (D).

(D) Piddi:ni

give.me.imp. widnak

your.ears.nom.

‘*Give me your ears'

'lend me your ears'

Both English and Arabic use the same expression to ask an addressee to concentrate or pay full attention to what is going to be said. The only difference is that Arabic uses the word / Piddi:ni/ 'give me' instead of 'lend me'/sallifni/ which is used in English.

This category will be briefly discussed because it is not 
challenging for human translators as the other two categories are but still they need to be properly fed into the data of machine translation programs.

\section{Key words:}

Body-parts expressions; Condemning; Praising; Translation gap; Machine translation; Cultural gap; Translation alternatives.

\section{Previous studies on body parts expressions:}

Menarko (2014: 195) focused on the relation between "mind" and "body" within the domains of English idioms. She believed that the importance of investigating idiomatic expressions in English arises from the fact that they specify linguistic and extra linguistic knowledge in a specific way.

Hasselgren (2015) also tackled body parts expressions and was interested in collecting different English expressions and idioms which employ body parts such as the knee, lips, leg and others were involved.. Hasselgren wrote in the introduction of his book that it was challenging for him to approach that issue from a linguist point of view since he is not a linguist but a surgeon. He summarized the reasons why he wrote his book in three points; for anatomy matters, his interest in the American language as a non-native speaker, and the fact that such expressions of body parts are strikingly used in daily situations that they captured his attention. Unfortunately, the current study couldn't depend on his work because he is not a linguist but, he only approached the matter from a non-linguistic point of view. 
Doeden, (2012) explored idioms in which body parts are used in a very interesting way, referring to the fact that an idiom is a group of words which have a meaning different from what you think they may mean. He linked that to the phenomenon of using various body parts expressions in a sense that has no relation with to parts employed. He analyzed several idioms with body parts commenting on the real meanings behind those expressions. Fox (2018) analyzed phrases describing parts of the body that are used when talking about inner subjective experiences such as feelings, thinking, remembering, and relating socially.

In Arabic, body parts expressions are also used excessively carrying the meanings of praising, condemning, insulting and also encouraging. According to Gaad (2006) most of the studies which tackled the issue of body parts expressions were interested in explaining these expressions when used as oaths, especially by God in the Quran. Other common expressions such as /wiHyaat ayu:nak/ '*for the life of your eyes', which is mainly used to show sincerity in giving promises were also tackled discussing the way body parts expressions can be used as oaths . Gaad (2006) concludes that such ways of swearing are common in the Arabic culture.

The present study focuses on presenting a selected number of Arabic idioms and expressions such as / Pi:di ala kitfak/ 'my hands are on your shoulder', /rastå lisaani min laghlu:ghuh/ I would cut 
off my tongue from its roots" in which various body parts are used to indicate meanings which are not related to the body parts used. The study is concerned with figuring out whether the English language behaves in the same way regarding those expressions or not. Whenever the expression has no equivalent in the target language, alternatives are suggested, to make sure that the message intended in the source language is delivered accurately without any ambiguity or deviation.

As far as the researcher knows, body parts expressions in English and Arabic haven't been deeply investigated from a linguistic point of view exploring the similarities and differences between the two languages in translation and offering ways to cross the cultural gap between them. It's important to state that, in Arabic, body part expressions have been investigated from a Qur'anic point of view in almost all the studies which tackled that issue exploring how Almighty God used different body parts in taking oaths (Abdulhai, 2016) ( Almasri, 2016).

The current study focuses on studying the issue of body parts expressions from a linguistic point of view highlighting the similarities and differences between the two languages concerning that phenomenon.

The significance of the present study can be summarized in the following points:

Firstly, it focuses on comparing the way body parts expressions behave in English and Arabic. 
Secondly, it investigates the way each body part expression is translated highlighting the difference in their behavior in the two languages.

Thirdly, it offers alternatives for the expressions which are unique in Arabic with no equivalent in English.

\section{Methodology:}

This study is an Arabic/ English contrastive study comparing the use of body parts expressions in the two languages exploring their meanings and whether they indicate something related to the body parts used or not.

Data are collected from informants, real life situations, Facebook, Twitter, TV talk shows, movies and series.

Each body part expression is literally and machine- translated. The machine translation programs used are Google translate, Microsoft Translator and Yandex.

The data collected are classified into three categories; the first one is that of body parts expressions used in the same structure to indicate the same meaning in both English and Arabic. The second is of those expressions which are used in Arabic, and have English equivalents which fail to deliver the messages intended by their Arabic counterparts. The third category is of these expressions which are only used in Arabic and neither have equivalents nor understood if translated literally. 


\subsection{Data and analysis}

In analyzing the data which are used in the study, the following steps are followed:

First: Arabic body part expressions which are used commonly in everyday situations are introduced phonologically.

Second: A syntactic representation of each expression is provided. Third: A semantic representation of each expression is represented.

Fourth: A comparison between the way each expression behaves in the two languages under investigation is drawn with reference to the way machine translation programs translated the expression Fifth: Alternatives are suggested for expressions which are not common in the English language.

The analysis of Arabic expressions is based on what Siny (1996) provided in his Lexicon idiomatic expressions Contextual Arabic.

\subsection{Research questions:}

The present research aims at answering the following questions:

1- What is meant by body parts expressions?

2- Why are they used?

3- Do English and Arabic behave in the same way regarding the phenomenon of body parts expressions?

4- What are the alternatives in case some body parts are unique in one language and vague in the other?

5- $\quad$ Do body parts expressions carry meanings which are not related to the body parts they use? 
6- $\quad$ Are there more than one meaning to some body parts expressions based on the context they are used in, or are the meanings fixed?

\section{Expressions that coincide in Arabic and English}

A limited number of expressions using the names of different human body parts are used approximately in the same exact way in Arabic and English. Such as

$\begin{array}{lll}\text { /PilPiid } & \text { lwaHdaha matsaPPafsh/ } \\ \text { the.hand.nom } & \text { alone.adv. } & \text { do.not.clab. }\end{array}$

'It takes two hands to clap'

The translation of such expressions from Arabic into English is not really challenging at all for human translators and also manageable for machine translation programs except for a limited number of expressions. Expressions that seem to be familiar to both Arabic and English reader are only going to be touched upon in this section because they already have equivalents in the target language which make the messages intended in the source language easily transmitted and comprehended by the target language readers.

Below is a sample of such Arabic expressions with both human translation and machine translation suggestions.
1)
PaT
lisa:n-(uh)
?illy
$y u ? u: l$
kidah 
cut. his.pro. who.pro. say.prsnt. that.dem.

inf. tongue...acc.

'His tongue shall be cut off for saying that'

"Cut out his tongue that says so" yandex translation

2) $\cap a T^{\mathrm{k}}$ (kasr) rijluh/

cut.inf. his.pro.

(break.inf.) leg.acc

'His leg shall be cut off (broken)...

'I will cut off his leg .....'

"Cut off his leg." Yandex translation

3) $/$ at $\mathrm{T}^{\mathrm{c}}$ (kasr) ?i:duh/

cut.inf his.pro.

(break.inf) hand.acc

'His hand shall be cut (broken).'

'I will break (cut off) his arm'

'I will have his hand cut (broken)

"Cut off his hand" Yandex translation

4) Jarjari:ha $\min$ shacrahal

you.pro.pull.v. from.prep. her.pro.hair.gen

pst. her.pro.

'Drag her by the hair'

"Pull her out of her hair" Google translation

5) /cala juththiti/

on.prep my.prodead body.gen 
'Over my dead body'

"On my body" Google translation

6) ${ }^{\mathrm{i}} \mathrm{i}: n i \quad f \quad$ cinak

my.pro.eye in.prep. your.pro.eye.gen.

'Look me in the eye'

"My eyes are in your eyes" Google translation

7) haksar ?albak

break.v.fut. your.pro.heart.ac

'I will break your heart'

"Break your heart"

8) Pakhazza? cini:k

I.gouge.prsnt your.eyes.acc

'I will gouge out your eyes'

"tear your eyes"

9) lisa:nuh Tawi:1

his.tongue.nom long.adj.

'He has a long tongue'

"His tongue is long: Google translation

10) yuHshur manakhi:ruh

stick.prsnt his.nose.acc.

'He pokes his nose '

"He sticks his nose" Google translation

11) /haghmizak (biSi:ni)

I.will.wink.fut. with.prep.my.eyes.gen 
'I will wink at you'

I wiggle you with my eyes" Google translation

The examples listed in that section is of body parts expressions that are translated into English easily since the idea of using such body parts to threaten, promise or disgrace are equally common in the two languages under investigation, and that's why these expressions are not going to be further investigated.

As for machine translation programs such as Google and Yandex, the previous expressions were not tricky, only a limited number of them were somehow misinterpreted, but as for the rest of the expressions, the translation output was accepted.

\subsection{Expressions which do not coincide either structurally or functionally in English and Arabic}

Unlike the previous section, this one explores expressions that are unique in Arabic with no equivalents in the English language and provides alternatives to bridge the cultural gap between the two languages in translation. Condider the flowing example:

$\begin{array}{llll}\text { /raafiS } & \text { manakhiiruh } & \text { fi } & \text { ssama/ } \\ \text { raise.v.prsnt } & \text { his.nose.acc } & \text { in.prep. } & \text { the.sky.gen }\end{array}$

'*He raises his nose up to the sky'

'he looked down his nose'

'He raised his head up to the sky'

Some Arabic body parts seem familiar to English readers if 
slightly changed in structure while others are used in the same structure in the two languages but functions differently.

Translating these expressions is not challenging for human translators but tricky for machine translation programs which fail to translate most of these expressions properly. Below are some Arabic expressions which have English counterparts but with either lexical or semantic difference.
12) $/$ Ta $11 a^{c}$
ru:Hi/
took.out.pst
my.soul.acc

'He took my soul out'

To take one's soul out is a familiar expression in both English and Arabic, but their usages are not quite the same since in Arabic it reflects mainly the speaker's boredom or dissatisfaction with a current situation or person while in English it shows great excitement and joy.

13) /haPta

I.will.cut.fut. nafasak/

your.breath.acc

'I will take your breath away'

In Arabic to take one's breath away means to make him so tired that he can't inhale air or as a threat to kill him. In English the same expression exists but with different indications since it is 
used as a sign of extreme amazement, surprise, joy and happiness.
14) Jyirmi
widnuh/
throw.prsnt
his.ear.acc
'*To drop one's ear'
'To keep his ear to the ground'

The expression /yirmi widn/ in Arabic means to spy and try to listen secretly to other people's conversation. The expression has an equivalent in English using different words 'To keep or have one's ear to the ground'.
15) /Piddi:ni
widnak/
give.imp.me
your.ear.acc
‘*Give me your ears'
'Lend me your ears'

Both variants are equally used in English and Arabic to ask the addressees to listen carefully to what the speakers are going to say. The only difference is that the term "lend" is used instead of "give" to indicate that meaning.
16)
lyirfac
?:duh
Min
ImaDu:c/
raise.v.
his.pro.hand
from.
the.art.topic.ge
prsnt.
prep
n

'*Raise his hand from the topic'

'Wash his hands out of this matter' 
The Arabic expression /yirfac ${ }^{c}$ i:duh min $1 \mathrm{maDu}: \mathrm{c} /$ carry the same meaning of the English counterpart "wash hands out of something".

\subsection{Arabic Body Parts Expressions which are unique in Arabic and vague in English.}

A great number of Arabic body parts expressions, especially those which are used to insult, promise, threaten or condemn, have no equivalents in the English language.

Such as

fawwar

boil.v.pst dammi

my.blood.acc

‘*He boiled my blood'

'He made me angry'

Translating such expressions as they are into English will be extremely ambiguous to the target language readers and using machine translation programs will be completely inappropriate unless proper data was fed into such programs.

Consider the following examples:
$17 \quad / ? a ? T^{c}$
lisa:ni
$\min$
laghlu:ghuh/
)
I.pro.cut.v.
my.arm.
from.gen
its.roots.gen 
prsnt. acc

'*I shall cut my tongue from its roots'

'I am pretty sure', 'I am certain'

/?a?Tac lis:ani min laghlu:ghuh/ is a common Arabic expression used to indicate that the speaker is so sure about what he is saying that he is ready to lose his arm if he was proven wrong.

The literal translation of that expression is actually vague since it is not common to use such an expression in English especially with the addition of the term/ laghluughuh/ or its counterpart 'its roots'

It can be translated as 'I am pretty sure' or 'I am definitely sure' to deliver the message of certainty intended in the original text. "I cut off my tongue from it" is the Google translation of the Arabic expression which is absolutely vague and misleading.

18)a

/ra?abti

my.neck.n. sadda:dah/

payer.n.

'*My neck is a payer' 'you can count on me', 'I am all yours'.

The same meaning also appears in the Arabic expression

18) a Tawwil

Lenghthen.v.imp

“*Lengthen my neck”

'Make me proud' ra?abti

My.neck.acc 
/ra?abti sadda:dah/ is an expression used to show the speaker's desire to look trust worthy and generous. It is used to clarify that the speaker is volunteering to pay everything he owes for the sake of his addressee.

The expression doesn't have an equivalent in the English language and the literal translation of it is actually meaningless. Alternatives carrying the meaning of trust and confidence such as 'you can definitely count on me 'can substitute it are suggested. My neck, plug it up" is the yandex translation version of the expression which is also meaningless.

19) a $/ \min \quad{ }^{c} i: n i \quad d i \quad$ ?abl di
from. my.eye. this.dem. before. this.dem. prep gen $\mathrm{adv}$

'*from this eye before that one'

'I will do everything I can'

“*From this eye before this one" Yandex Translation

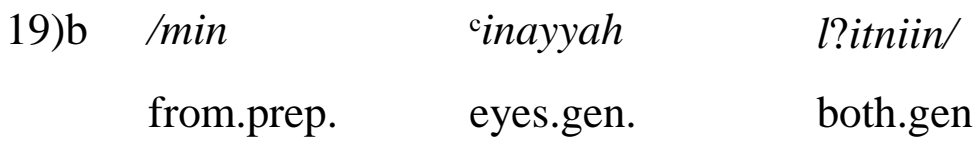

'*from my both eyes'

'consider it done'

“*From the two eyes" Google translate

Both expressions show the speaker's unquestioned desire to help or give his addressee whatever he wants. The idea of giving 
someone something from one or both eyes is unfamiliar to the English reader; that's why alternatives delivering the same message intended in the source language are offered.

20) /xa:tim ring.nom.

'*A ring in my finger'

'He is under my authority'

To make someone as a ring around a person's finger is a very common Arabic expression indicating that the addressee has ultimate control and power over someone who obeys him blindly.

21)
/wiHyaat
shanabi/
by.prep.life my.pro.moustach.gen.

'*By the life of my moustache'

'I swear'
lyib?a
shanabi
become.v. prst. nom
This moustache will be on a woman'
'don't call me a man if ....'
'I shall not be called a man if....'

$d a$

${ }^{c} a l a$

marah/

my.pro.moustach.

that.dem.

on.prep.

woman .gen

'I swear' 
The expressions /wiHya:t shanabi/, and /yib?a shanabi da cala marah/in Arabic are used mainly to threat

$$
\begin{array}{ll}
\text { sawwid } & \text { wishshi } \\
\text { blacken.v.pst. } & \text { my.pro.face.acc }
\end{array}
$$

'*He blackened my face'

'He embarrassed me'

$$
\begin{array}{ll}
\text { bayyaD } & \text { wishshi } \\
\text { whiten.v.pst } & \text { my.pro.face.acc }
\end{array}
$$

'*He whitened my face'

'He made me proud'

The two expressions above are used in Arabic in a large context; the earlier is used when the speaker feels unappreciated and underestimated because of someone's failure and omission. While the latter is used to indicate the exact opposite meaning since it reflects the speaker's pride and satisfaction of someone's perfection.

The two expressions are somehow vague to the English reader since their literal translations provide a different meaning than the one intended in the source language. To whiten a face in English is to make it brighter using a specific product, for instance, while blackening a face means to make it darker out of burns or bruises. To avoid altering the message intended in the source language 
using these expressions, alternatives are used such as: 'He made me proud' or 'He embarrassed me'.

$$
\text { /harfac ra:sak/ }
$$

raise.v.fut. $\quad$ your.pro.head.acc

‘*I will raise up your head'

'I will make your proud'

To raise another one's head in Arabic is to make his proud and happy, but the English lateral equivalent doesn't imply that meaning, but it rather means the actual movement of the head upwards. 'I will make you proud' indicates that meaning of pride and happiness.

26) Ixarram

puncture.v.imp. wida:nak/

your.pro.ears.acc

‘*Pierce your ear'

'Get ready', 'consider it done'

$$
\begin{array}{ll}
\text { /wa??af } & \text { lmaka:n } \\
\text { stop.v.pst. } & \text { the.place.ac }
\end{array}
$$

${ }^{\mathrm{c}}$ ala

rijl

$w a \mathrm{H} d a h /$

on. prep. foot. gen

one. gen

c.

'*He made them all stand on one leg'

'He frightened them to the bone', 'They were all ears', 


$\begin{array}{lll}\text { /haHutTTuh } & \text { that } & \text { Dirsi } \\ \text { I.will.put.prsnt. } & \text { under.prep. } & \text { my.grinder. } \\ \text { him.acc } & & \text { gen }\end{array}$

‘*I will put him under my grinder'

'Will torture him'

The expressions in (27 and 28) are unique to the Arabic language and have no equivalents in the English language. Such expressions are used to indicate the speaker's ultimate anger towards someone that he is going to make him hurt so much and apply painful strength to hurt him. Since such expressions have no equivalents in English, alternatives such as 'I will make his curse the day he was born', 'I will torture him' or 'I will make him regret doing...' are suggested.

29 ImaPSu:f

cut.adj

'*With a broken neck'

'impolite', 'indecent'
rraPabah/

the.neck.acc

To describe someone with having a broken neck in Arabic suggest that he has done or said something that his addressee didn't like and found so shameful and obscene. That expression is particularly used to refer to kids who are just a little bit naughty. Since such description is meaningless in English synonyms such 
as rude, impolite or indecent are used to deliver the message intended in the source language.

30

/xa:tim

F

Suba:ci/

ring.nom.

in.prep.

my.finger.gen

'*A ring in my finger'

'He is under my authority'

To make someone as a finger in one's hand or a ring around person's finger is a very common Arabic expressions gr indicating that the addressee has ultimate control and power over someone who obeys him blindly. The English literal translation 'A ring in my finger' doesn't deliver that message intended in the source text thus alternatives such as 'I got him controlled', 'He is all mine ', 'He blindly obeys me' will succeed on delivering such a message.

$\begin{array}{llll}\text { simict } & \text { rraSd } & f & \text { wda:nak } \\ \text { hear.pst } & \text { thunder.acc } & \text { in.prep. } & \text { your.ears.gen }\end{array}$

"*you heard thunder in your ears'

'I wish you were deaf', 'you shouldn't have listened to ...'

The Arabic expression in (31) is used to express extreme anger towards an addressee who has actually listened to something he was not supposed to listen to or he listened to something but 
didn't actually do what he was told to do. The expression is very common in Arabic but is meaningless in English thus alternatives that provide that meaning should be used in order to avoid the ambiguity of literal translation.

\section{Findings and Conclusions}

These are the findings and conclusions of the study:

1- $\quad$ Body parts expressions are those expressions in which a body part is used to indicate meanings irrelevant to the body part used but meant to express different feelings and altitudes.

2- $\quad$ Arabic and English have some body parts expressions which behave in the same way.

3- Some Arabic body parts expressions have an equivalent in English but with different meaning full stop

4- Some Arabic expressions are unique with no equivalents in English

5- $\quad$ Alternatives for such unique expressions are suggested in order to bridge the cultural gap between the two languages and to avoid any deviation of the source message.

Arabic and English employ body part expressions in a wide range. Throughout the study some of the most commonly used Arabic body parts expressions have been introduced. These Arabic expressions have been categorized into three different classes; the 
first class includes expressions which are commonly used in the two languages and this is the most unproblematic class since such expressions can be easily translated into English as in (32) blow

32) /PilPiid

the.hand.nom
lwaHdaha

alone.adv.
matsa?Pafsh/

do.not.clab.

'It takes two hands to clap'

The second class is that of Arabic expressions which are familiar to the English readers but either with different structure or with a different meaning as in (32).

$$
\begin{array}{ll}
\text { /raafis } & \text { manakhiiruh } \\
\text { raise.v.prsnt } & \text { his.nose.acc }
\end{array}
$$$$
\text { fi }
$$$$
\text { ssama/ }
$$$$
\text { in.prep. }
$$$$
\text { the.sky.gen }
$$

'*He raises his nose up to the sky'

'he looked down his nose'

'He raised his head up to the sky'

The idea of one being arrogant looking at people in a superior way is both common in the two languages but through different expressions as seen in above.

The third category is of those Arabic expressions which are only used in Arabic and have no equivalents in English as in (34). This is the trickiest class since it needs full awareness of the cultural gap between the two languages' 
34) fawwar boil.v.pst dammi

my.blood.acc

'*He boiled my blood'

'He made me angry'

Arabic seems to use some expressions which are only understood among those who are familiar with the Arabic culture. Such expressions are totally vague for the English readers and that requires the translator to use alternatives or non- literal translation of such expressions in order to avoid any ambiguity in the target language text.

An expression such as

$$
\begin{array}{ll}
\text { / ra?abti } & \text { saddaadah/ } \\
\text { my.neck.n. } & \text { payer.n. }
\end{array}
$$

‘*My nick is a payer’

'you can definitely count on me'

"I will support you all the time'

The expression above is completely unique in Arabic and it has no counterpart in English which makes a literal translation such as 'my nick is a payer 'completely vague and meaningless since that common expression is only understood for those who are familiar with the Arabic language. In order to avoid such an ambiguity a 
non-literal translation is suggested such as 'Consider it done, or 'I will pay whatever it takes'

Such alternatives convey the intention of the speaker's desire to give whatever his addressee needs.

Other expressions are used in the same way in the two languages under investigation such as

36

$$
\begin{array}{lll}
\text { ci:ni } & \mathrm{f} & \text { cinak } \\
\text { my.pro.eye } & \text { in.prep. } & \text { your.pro.eye.gen. }
\end{array}
$$

'Look me in the eye'

This expression is used in the two languages to indicate that the speaker is trying to make sure from his addressee's loyalty and truthfulness by asking the addressee to look him in the eyes Translating Arabic body parts expressions which has no equivalents in English is really changing since a translator should keep in mind that there is a cultural gap between the two languages under investigation and that such a gap should be bridged in order to avoid any ambiguity or confusion in the target language text.

\section{Originality}

The present paper focuses entirely on how a single aspect of the phenomenon of body parts expressions behave in the two languages under investigation depending on the analysis of data used commonly by informants in daily occasions. 


\section{Significance/Implications}

The significance of this paper lies in the fact that the issue of body parts expressions haven not been discussed from a linguistic point of view in English and Arabic, as far as the researcher knows. The study focuses on the different ways body parts expressions are used to indicate meanings which have nothing to do with the body part involved in them and how to bridge the gap between the two languages in translation especially the mechanized one.

\section{Limitations}

The limitations of this study are that the researcher wasn't able to discuss all body parts expressions but only a few of them. The Expressions which behave in the same way in the two languages under investigation are only touched upon while the expressions which are unique in Arabic are illustrated offering the most adequate versions of translation to convey the messages intended in the source text. 
Appendix

\section{Phonemic Symbols}

The Phonemic Symbols that will be used to represent the Arabic data in the study are listed below with their corresponding Arabic graphemes.

\begin{tabular}{|c|c|c|}
\hline /b/ & Voiced bilabial stop & /ب/ \\
\hline$/ t /$ & Voiceless alveo-dental stop & 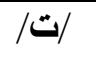 \\
\hline /T/ & $\begin{array}{l}\text { Voiceless alveo-dental } \\
\text { velarized stop }\end{array}$ & /b/ \\
\hline$/ \mathrm{d} /$ & Voiced alveo-dental stop & $/ /$ \\
\hline /D/ & Voiced alveo velarized stop & |ض/ \\
\hline$/ \mathrm{k} /$ & Voiced velar stop & /ك/ \\
\hline /q/ & Voiceless uvular stop & /ق/ \\
\hline /?/ & Voiceless glottal stop & $|\&|$ \\
\hline$/ \mathrm{j} /$ & Voiced alveo-palatal fricative & /ج/ \\
\hline$/ \mathrm{H} /$ & Voiceless pharyngeal fricative & / I \\
\hline 4 & Voiced pharyngeal fricative & / اع/ \\
\hline /f/ & Voiceless labio-dental fricative & /ف/ \\
\hline$/ \mathrm{th} /$ & Voiceless dental fricative & / / \\
\hline$/ \mathrm{d} /$ & Voiced dental fricative & / \\
\hline /TH/ & $\begin{array}{l}\text { Voiced dental velarized } \\
\text { fricative }\end{array}$ & |ظ/ \\
\hline$/ \mathrm{s} /$ & Voiceless alveolar fricative & /س/ \\
\hline$/ \mathrm{S} /$ & Voiceless alveolar velarized & |ص/ \\
\hline
\end{tabular}




\begin{tabular}{|c|c|c|}
\hline & fricative & \\
\hline $\mid \mathrm{z} /$ & Voiced alveolar fricative & 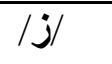 \\
\hline$/ \mathrm{sh} /$ & $\begin{array}{l}\text { Voiceless alveo-palatal } \\
\text { fricative }\end{array}$ & |ش/ \\
\hline$/ \mathrm{x} /$ & $\begin{array}{l}\text { Voiceless alveo-palatal } \\
\text { fricative }\end{array}$ & $\mid \dot{\mathrm{C}} /$ \\
\hline /gh/ & Voiced uvular fricative & |غ | \\
\hline$/ \mathrm{h} /$ & Voiced glottal fricative & 101 \\
\hline$/ \mathrm{r} /$ & Voiced alveolar trill & 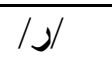 \\
\hline$/ 1 /$ & Voiced alveolar lateral & $/ \mathrm{d} / \mathrm{d}$ \\
\hline$/ \mathrm{m} /$ & Voiced bilabial nasal & /a/ \\
\hline$/ \mathrm{n} /$ & Voiced alveolar nasal & /ن/ \\
\hline$/ \mathrm{y} /$ & Voiced palatial glide & /ی/ - - إ/ \\
\hline$/ \mathrm{w} /$ & Voiced bilabial round glide & /و/ \\
\hline /i/ & High front vowel & كسرة| \\
\hline /a/ & Low back vowel & فتحة \\
\hline$/ \mathrm{u} /$ & High back rounded vowel & ضمة \\
\hline
\end{tabular}

Note: Consonant germination and vowel length are represented by doubling the respective consonant or vowel. 
مجلة كلية الآداب جامعة الفيوم اللغويات والثقافات المقارنة) مج 13، ع1 (يناير) 2021

\section{References:}

Almasri, Tantawi Guhari. 2016. /tafsiir t $\square$ ant $\square$ aawi guhari

(Palgawaahir fi tafsiir lqur?aan lkariim/, 13-1. 9. Dar Al Kotob Al Ilmiyah

Doeden, Matt. 2012. Stick Out Like a Sore Thumb: And Other Expressions about Body Parts, It's Just an Expression. Lerner Publications.

Fox, James J. 2018. Expressions of Austronesian Thought and Emotions, Comparative Austronesian Series. ANU Press

Gaad, Moatsafa. 2006. /mukniz Palfulklore/.1. ktab INC.

Gallab, Abdullahi A. 2018. Hasan al-Turabi, the Last of the Islamists: The Man and His Times 1932-2016. Rowman \& Littlefield.

Hasselgren, Per-olof. 2015. Body Language from Head to Toe. Strategic Book Publishing \& Rights Agency.

Seny, Mahmoud Ismail,1996./?al mu'jam ?alsyaaqi lilta'biiraat ?al?iSTilaaHyya/, Lebnan library publishers 


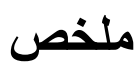

تهتم الدر اسه الحاليه بدراسه التعبيرات التي تضمن أجز اء الجسم و التي تستخدم لتدل

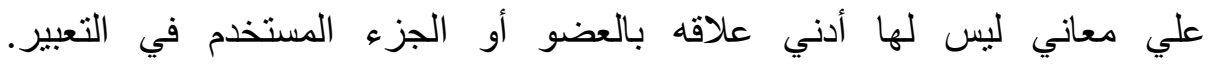

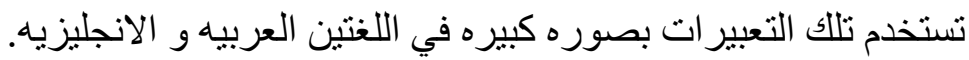

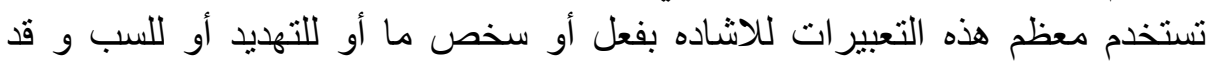

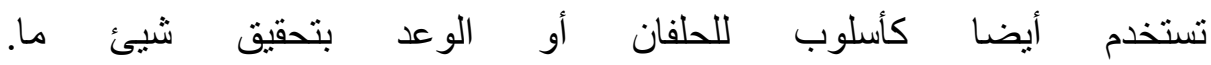
تستخدم اللغتان قيد البحث و الدراسه تلك الأساليب بكثره و لكن في كثثر من الأحيان

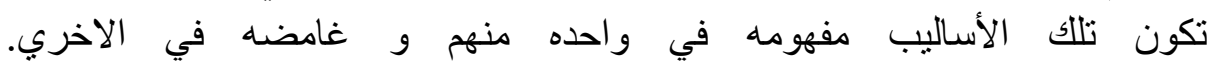

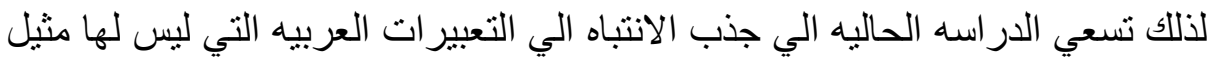

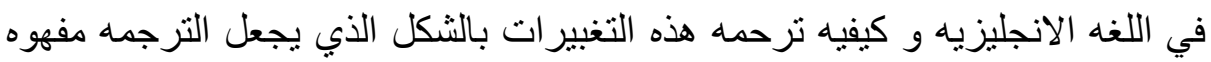
من القر اء و يوصل المعني المر اد دون أبي اتحر اف أو أو تشويها.

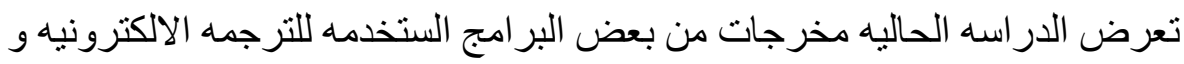
يقدم بدائل لتلك الترجمات ان كان هناك فجوه بين اللغتين المترجم منهاو الئه اليها. 